\title{
IMPLEMENTASI METODE WATERFALL PADA PERANCANGAN SISTEM INFORMASI PERPUSTAKAAN
}

\author{
Adi Nurseptaji ${ }^{1}$, Arey $^{2}$, Fadila Andini ${ }^{3}$, Yudi Ramdhani ${ }^{4}$ \\ ${ }^{1-4}$ Program Studi Sistem Informasi, Fakultas Teknologi Informasi, Universitas Adhirajasa Reswara Sanjaya \\ Email: ${ }^{1}$ adinurseptaji@gmail.com, ${ }^{2}$ areydjuanas08@gmail.com, ${ }^{3}$ fadilaandini1@ gmail.com, ${ }^{4}$ yudi@ars.ac.id
}

(Naskah masuk: 8 April 2021, diterima untuk diterbitkan: 11 Mei 2021)

\begin{abstract}
Abstrak
Sistem Informasi Perpustakaan merupakan gabungan melalui teknologi informasi dan juga aktivitas manusia mengacu pada interaksi antar manusia dan teknologi pada proses algoritma, data, informasi dan juga teknologi dukungan operasi untuk manajemen dalam pengolahan data dan juga informasi sehingga menghasilkan informasi yang bermanfaat. Pada saat ini pengelolaan perpustakaan masih sering terjadi kesalahan, kerusakan data, serta kesulitan menemukan informasi data, seperti data anggota, data buku, data peminjaman buku, data pengembalian buku dan data yang berkaitan dengan perpustakaan dikarenakan pengelolaan data dan informasi pada perpustakaan masih sangat konvensional. Sistem Informasi Perpustakaan bertujuan untuk mempermudah proses pengolahan data dan juga informasi yang ada pada perpustakaan khususnya petugas perpustakaan serta mempermudah peminjam buku untuk menerima berbagai informasi buku yang ada perpustakaan. Dengan menggunakan metode waterfall yang merupakan sebuah metode klasik yang bersifat sistematis secara berurutan dalam membangun perangkat lunak mulai dari tahap analisis masalah dan analisis kebutuhan fungsional sistem, tahap desain menggunakan unified modeling language (UML) seperti use case diagram, activity diagram, sequence diagram, hypertext preprocessor (PHP) sebagai bahasa pemrograman, pengujian sistem menggunakan blackbox testing dan maintenance sistem. Sistem Informasi Perpustakaan dapat meminimalisir kesalahan, mempermudah dan mempercepat kemampuan petugas dan peminjam buku untuk mendapatkan informasi yang dibutuhkan yang ada pada perpustakaan pembuatan laporan dapat lebih real time, efektif dan efisien. Sistem informasi Perpustakaan harus selalu di maintenance secara berkala sesuai dengan kebutuhan $u$ ser.
\end{abstract}

Kata kunci: Sistem Informasi, Perpustakaan, Metode Waterfall, UML, Website

\section{WATERFALL METHOD IMPLEMENTATION IN DESIGN LIBRARY INFORMATION SYSTEM}

\begin{abstract}
The Library Information System is a combination through information technology and human activities referring to the interaction between humans and technology in the process of algorithms, data, information and also operating support technology for management in data processing and information so as to produce useful information. At this time library management still often occurs errors, data damage, and difficulty finding data information, such as member data, book data, book borrowing data, book return data and data related to libraries because the management of data and information in libraries is still very conventional. The Library Information System aims to facilitate the processing of data and information in libraries, especially librarians, and to make it easier for book borrowers to receive various information on books in the library. By using the waterfall method which is a classic method that is sequentially systematic in building software starting from the problem analysis stage and system functional requirements analysis, the design stage uses unified modeling language (UML) such as use case diagrams, activity diagrams, sequence diagrams, hypertext preprocessor (PHP) as a programming language, system testing uses blackbox testing and system maintenance. The Library Information System can minimize errors, simplify and accelerate the ability of officers and book borrowers to get the information needed in the library making reports can be more real time, effective and efficient. Library information systems must always be maintained periodically according to user needs.
\end{abstract}

Keywords: Information Systems, Libraries, Waterfall Methods, UML, Website

\section{PENDAHULUAN}




\begin{abstract}
Menyambut era revolusi industri 4.0 berbagai jenis teknologi informasi sudah mulai diimplementasikan sesuai dengan jenis kebutuhannya Dunia terus mengembangkan kecanggihan dari teknologi informasi termasuk Indonesia karena dengan adanya teknologi informasi dengan pemanfaatannya manusia dapat mudah dan cepat melalukan proses pengelolaan data ataupun informasi yang ada pada sebuah organisasi. Teknologi Informasi terdiri dari sesuatu hal yang berdampingan bersama manipulasi data ataupun pengelolaan informasi. Sedangkan Teknologi Komunikasi terdiri dari sesuatu hal yang berdampingan dengan suatu proses penyampaian dan pengiriman berbagai informasi melalui pengirim kepada penerima. Dari pendapat teknologi informasi ataupun teknologi komunikasi, kedua teknologi tersebut saling berkaitan erat satu sama lain dan tak terpisahkan, Teknologi Informasi dan Komunikasi ialah semua bentuk suatu kegiatan yang dapat terkait bersamaan dalam proses manipulasi, pengelolaan, dan pemindahan informasi melalui pengirim kepada penerima (Simarmata, 2021).
\end{abstract}

Teknologi Informasi merupakan bagian penting dalam suatu organisasi. Apalagi pada masa disrupsi dan situasi yang dinamis pada saat ini, TI sudah membuat fasilitas yang utama khususnya organisasi agar dapat terwujudnya efisiensi pada sebuah operasional dan dapat mencapai kualitas yang kompetitif. Maka dari itu, rancangan prosedur TI yang efektif paling diperlukan agar dapat menentukan pada proses pembentukannya bisa berjalan sesuai bersama nilai, visi misi dan tujuan yang ada pada sesuatu organisasi tersebut. Sama halnya dan tanpa pengkhususan Universitas merupakan bagian dari organisasi pendidikan yang sampai saat ini menggunakan TI sebagai fasilitas pengelolaan aktivitas akademis agar dapat mewujudkan kualitas yang optimal dan dapat menyediakan pelayanan yang unggul kepada pemangku yang berkepentingan (Agustiono et al., 2021).

Teknologi Informasi suatu elemen yang berkaitan dengan sistem informasi berlandaskan komputer dan juga dari teknologi informasi yang ada kaitannya pada sebuah teknologi. Hal yang paling utama perangkat keras, perangkat lunak, dan sebuah jaringan telekomunikasi. Berupa bentuk nyata (tangible) teknologi informasi seperti dengan server, personal computer (PC), router, dan kabel jaringan, adapun bentuk tidak nyata (intangible) seperti berbagai jenis tipe software (W. A Probonegeoro, 2021)

Saat ini perkembangan dunia yang semakin modern, teknologi juga ikut membagikan peran penting dari aspek komunikasi ataupun korelasi sosial. Teknologi telekomunikasi sangat dibutuhkan untuk sarana penghubung antar manusia untuk kebutuhan berbagai informasi ataupun kebutuhan sosial. Telekomunikasi mengandung nilai sosial dan sangat memungkinkan dari individu menggabungkan, mengerjakan, ataupun saling bertukar informasi melalui individu lain (Amelia et al., 2020)

Teknologi sebagai medium dalam kemajuan elektronik yang bisa mengubah cara hidup manusia dan sangat mempengaruhi terutama khususnya dalam bidang pekerjaan. Karena dengan penerapan teknologi pada sebuah organisasi sangat membantu untuk meningkatkan sebuah prestasi dalam bidang pekerjaan berbanding jika hanya mengandalkan terhadap tenaga kerja yang primitif. Kebiasaan masyarakat sering menganggap teknologi suatu alat yang dapat berfungsi agar meningkatkan sebuah hasil dari suatu produk semacam pemanfaatan robot. Namun, teknologi bisa dikategorikan menjadi sistem informasi ataupun multimedia semacam komputer, internet, jalur lebar ataupun halaman sosial yang dibuat agar memudahkan dalam suatu bidang pekerjaan dan bisa meningkatkan produktivitas yang ada pada organisasi. Maka dari itu, pemanfaatan dari teknologi semakin terus diterapkan karena bisa mengurangi kesalahan serta lebih cepat dan relevan. Pemanfaatan teknologi informasi dan komunikasi atau Information and Communications Technology (ICT) pada era digital ini telah menjadikan kesempatan pada berbagai individu terutama pada golongan pekerja agar bisa belajar dan bagaimana cara mengimplementasikan keahlian yang sangat diperlukan pada abad 21 ini. Tanpa adanya wawasan dan keahlian yang relevan dengan ICT, seorang individu relatif sulit agar dapat berdampingan dengan era modern ini. Karena demikian kebutuhan pada bidang pekerjaan yang setiap waktu dapat berubah dan sudah seharusnya pekerja terus meningkatkan keahlian dan juga keterampilan yang dibutuhkan pada sebuah organisasi. Pemanfaatan dan juga bagian dari teknologi informasi dan komunikasi sangat berdampak pada prosedur komunikasi yang ada pada sebuah organisasi. Dapat disimpulkan bahwa sebuah organisasi yang mampu mengimplementasikan ICT, akan bisa meningkatkan dalam mencapai objektif dan dapat memenuhi daya saing pada sebuah organisasi. Pemanfaatan ICT pada sebuah organisasi bukanlah suatu hal yang asing, dengan begitu akan dapat mempermudah interaksi antar sesama yang ada pada organisasi dan dapat dimanfaatkan untuk perantara menyampaikan berbagai informasi dan membantu melaksanakan perintah yang ada pada organisasi. Pekerja yang dapat memiliki keahlian dan wawasan yang luas dalam hal ICT dapat mendukung peningkatan prestasi yang ada pada organisasi tersebut. Organisasi juga sangat perlu mengadakan pembelajaran tentang ICT secara berkala agar pekerja menjadi tidak terlambat dalam penggunaan teknologi yang sudah tersedia sehingga sehingga dapat berpengaruh pada kualitas serta produktivitas dan bisa mencapai prestasi. Organisasi yang dapat menerapkan ICT bisa meningkatkan kemahiran para 
pekerja terutama golongan pekerja berpengalaman (Lamsah, 2021)

Hadirnya suatu teknologi tentunya telah mengubah pola sistem pekerja dalam organisasi yang ada pada perpustakaan, berawal pada pola pekerja yang sangat konvensional dan juga primitif dituntut untuk menjadi lebih terkomputerisasi dan lebih modern. Dengan teknologi informasi perpustakaan sangat berdampak dalam pengelolaan berbagai jenis informasi yang sudah tersedia ataupun yang sudah disiapkan pada perpustakaan sehingga bisa memenuhi kebutuhan berbagai jenis informasi perpustakaan terhadap pemustaka yang semakin tinggi. Saat ini teknologi informasi sudah memperoleh nama baik dalam menyampaikan berbagai informasi kepada seseorang yang membutuhkan, pemustaka bisa memiliki akses jaringan untuk mencari katalog buku pada perpustakaan, basis data online, berbagai jenis informasi yang tidak terhitung berapa banyaknya dan juga dapat diakses kapanpun dan dimanapun. Penerapan teknologi informasi perpustakaan tidak bisa dapat penolakan keberadaannya, lalu para pustakawan yang telah umum dengan teknologi tentunya akan meminta penerapan pelayanan berteknologi informasi yang bisa mengakomodasi para pustakawan untuk mendapatkan informasi yang dibutuhkan (Fahrizandi, 2020)

Sebuah organisasi terutama Perpustakaan bagian dari institusi layanan masyarakat yang melayani kebutuhan proses transaksi peminjaman buku untuk keseharian. Pembagian pelayanan ataupun langkah untuk berbagai hal tentu berdampak pada peminjaman buku. Semakin meningkatkan layanan akan lebih baik lantaran melibatkan peminjam buku untuk mendapatkan ruang buku referensi yang tersedia. Semakin memberikan pelayanan jasa yang besar pada perpustakaan, maka akan lebih kompleksitas untuk memberikan jenis langkah serta pelayanan pada semua dengan tetap memberikan kesatuan pengorganisasian yang terpadu. Selain menyampaikan pelayanan pada perpustakaan dan juga perlu pengelolaan buku berupa katalog ataupun referensi buku agar dapat memastikan korelasi buku dan referensi tersimpan pada bagian mana pada perpustakaan. Mengantisipasi kondisi yang ada pada perpustakaan, sudah selayaknya perpustakaan memanfaatkan perkembangan teknologi komputer, seperti sebuah perangkat lunak ataupun perangkat keras untuk membangun sistem manajemen yang lebih dulu belum dapat diterapkan (Christianto \& Santosa, 2018)

Proses peminjaman buku ataupun pengembalian buku dengan sistem manual dan konvensional bukanlah hal yang salah, hanya saja perlu dipertimbangkan karena memiliki resiko sering terjadinya keterlambatan dalam hal pencarian buku yang dibutuhkan, hilangnya buku yang dibutuhkan, terjadinya kelalaian dalam proses pencatatan berbagai jenis data yang ada pada perpustakaan seperti saat peminjaman buku ataupun pengembalian buku kemudian pada proses pencarian buku yang masih konvensional dibutuhkan waktu yang relatif lama dari hal tersebut pada proses pengelolaan data dan informasi yang ada pada perpustakaan memerlukan waktu yang lama sehingga terjadi penurunan kualitas layanan yang ada pada perpustakaan (Chaidir, Indra, 2020)

Menggunakan pemanfaatan teknologi informasi, saat ini sistem informasi perpustakaan sangat menunjang berbagai jenis aktivitas yang ada pada sebuah perpustakaan terutama dalam pengelolaan data yang ada pada perpustakaan, yang kemudian dapat membagikan pelayanan yang sangat efektif serta efisien bagi anggota perpustakaan (Nurmansyah, 2021).

Penelitian terdahulu yang dilakukan oleh (Rahmawati \& Bachtiar, 2018) dengan judul "Analisis dan perancangan sistem informasi perpustakaan sekolah berdasarkan kebutuhan sistem". Pada rancangan sistem menggunakan diagram konteks dan data flow diagram (DFD). Pada penelitian ini desain rancangan sistem informasi perpustakaan penulis menggunakan tools unified modeling language (UML) seperti use case diagram, activity diagram, sequence diagram.

\section{METODE}

\subsection{Teknik Pengumpulan Data}

Menurut (Effendy \& Sunarsi, 2020) mengemukakan bahwa Teknik Pengumpulan Data adalah teknik utama pada suatu penelitian, berawal dari memperoleh suatu data merupakan maksud utama dari adanya suatu penelitian, tanpa mengenal dari teknik pengumpulan data, sudah dapat dipastikan bahwa peneliti tidak dapat memperoleh data yang bisa melengkapi standar dari data yang telah ditetapkan.

Pada penelitian ini penulis menggunakan tiga teknik pengumpulan data menurut (Rada, 2021) diantaranya:

1. Observasi, teknik pengumpulan data dengan cara melakukan pengamatan langsung pada kondisi ataupun situasi pada suatu subjek pada penelitian.

2. Wawancara, teknik pengumpulan data ini dilakukan dengan mengemukakan sebuah pertanyaan ataupun tanya jawab langsung pada subjek penelitian.

3. Studi Pustaka, teknik pengumpulan data dengan menggunakan buku, jurnal ilmiah, ataupun berbagai jenis sumber yang kredibel dan relevan dengan penelitian sistem informasi perpustakaan.

\subsection{Metode Pengembangan Software}

Pengembangan software ini penulis menggunakan metode waterfall, point yang begitu vital, krusial untuk pengembangan pada sebuah 
proyek Systems Development Life Cycle (SDLC). Model SDLC pada waktu manajer proyek dapat memperkirakan berhasil atau tidaknya suatu proyek tersebut. Waterfall merupakan model yang awal digunakan dan sangat umum pada proses pembuatan project pada instansi ataupun industri yang besar. Waterfall mementingkan dokumentasi dan model ini layak pada proyek yang mengutamakan kualitas (Maulia Usnaini, 2021) Sedangkan menurut (Irwanto, 2021) mengemukakan bahwa Waterfall menggambarkan Pengembangan suatu model yang menyajikan proses aturan hidup software dengan sistem yang berpengaruh bisa disebut dengan berurutan dengan mendahului proses analisis, desain, pengkodean, pengujian dan serta bagian pendukung. Menurut (Maulia Usnaini, 2021) mengemukakan bahwa waterfall terdapat beberapa tahapan sebagai berikut:

1. Analisa Kebutuhan, Hambatan ataupun harapan user merupakan gabungan untuk menjalankan rancangan sebuah sistem agar bisa dikerjakan sesuai dengan kemiripan yang diinginkan.

2. Rancangan Sistem, Tahap ini merupakan implementasi dari tahapan analisis kebutuhan yang kemudian dibuatkan perancangan dengan memanfaatkan hardware ataupun software pada komputer.

3. Implementasi, Merupakan implementasi dan aplikasi yang berawal dari kombinasi sistem yang telah direncanakan pada proses sebelumnya, dan kemudian menjalankannya dari bagian pertama menjadi program kesatuan.

4. Testing, Pemeriksaan program yang telah direncanakan dan dipersatukan kemudian menguji program tersebut apakah sudah siap dan sesuai dengan kebutuhan yang awalnya telah direncanakan. Sedangkan tahapan prosedur pengembangan software jenis waterfall menurut (Solichin, 2021) yang terdiri dari beberapa tahapan sebagai berikut ini:

1. Analisa Kebutuhan, Berawal dari tahapan menjabarkan terhadap sebuah sistem yang kemudian akan dirancang sesuai seperti apa dibutuhkan oleh rancangan sistem tersebut, seperti kebutuhan dari analisis hardware, software, dan juga kepentingan proses, input ataupun output dan analis kepentingan data dan proses pengumpulan sebuah data.

2. Desain, Tahapan setelah analisis yang telah ditentukan sebelumnya secara keseluruhan berdasarkan kebutuhan yang kemudian melakukan proses desain sistem yang kemudian akan diterapkan, dengan menggunakan Unified Modelling Language (UML) sebagai desain sebuah software. UML yang digunakan seperti Use Case Diagram dan Activity Diagram.

3. Coding, Tahapan coding ini disesuaikan dengan kebutuhan pembuatan sistem informasi yang akan diterapkan dengan memanfaatkan bahasa pemrograman Hypertext Prepocessor (PHP).

4. Pengujian (Testing)
Terdapat dua pendekatan dalam tahapan pengujian seperti Alpa testing dan Beta Testing yang akan diuraikan berikut ini:

a. Pengujian Alpa (alpa test), Pengujian ini dijalankan oleh perwakilan pengembangan sistem dari pakai akhir untuk menulis kesalahan ataupun masalah dari penggunaan sistem itu sendiri. Langkah pada pengujian alpha berpusat pada metode BlackBox dengan menguji fungsional dari software yang akan diterapkan dan menguji seluruh bagian elemen agar sesuai sebagaimana fungsinya ataupun tidak.

b. Pengujian Beta (beta test), Pengujian akhir yang mengikutsertakan tiga puluh responden sebagai pakai akhir serta membagikan kuesioner pada kelompok pengguna umum bersumber pada parameter sampel yang cukup.

\section{HASIL DAN PEMBAHASAN}

\subsection{Use Case Diagram}

Untuk menggambarkan fungsional pada sebuah sistem penulis menggunakan use case diagram. Diagram Use Case mewujudkan atau menggambarkan hubungan satu atapun lebih aktor terhadap sistem yang akan diterapkan (Nurmansyah, 2021). Use Case Diagram berperan sebagai gambaran dari berbagai gabungan use case case ataupun aktor pada sistem yang akan dibangun. Use Case Diagram berfungsi untuk pengelompokan ataupun pemodelan pada tindakan sistem yang pengguna inginkan (Herlita, Yoland, 2021). Diagram Use Case dapat menampilkan fungsionalitas pada sistem ataupun kelas dengan cara sistem berinteraksi pada dunia luar juga menguraikan sistem sebagai fungsional dan terpandang pada aktor (Hartopo, Sofian Winardi, 2020).

\subsection{Use Case Diagram Sistem Informasi Perpustakaan Usulan}

Adapun proses kegiatan pengelolaan sistem perpustakaan yang digambarkan melalui Use Case Diagram sistem informasi perpustakaan yang diusulkan sebagai Gambar 1.

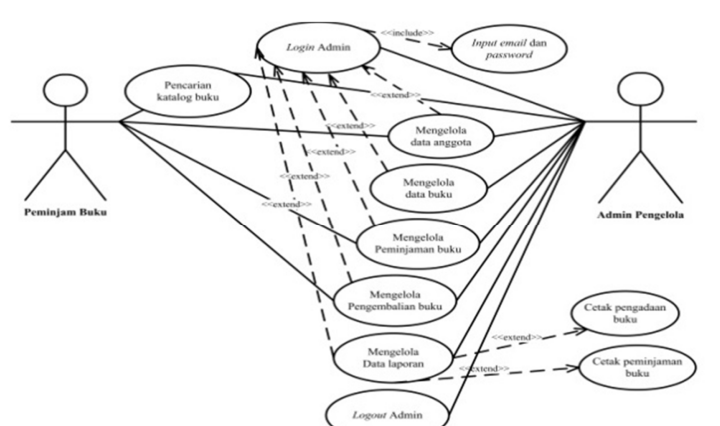


Gambar 1 Use Case Diagram sistem informasi perpustakaan

\subsection{Analisa Kebutuhan Software.}

A. Halaman Katalog Pencarian Buku:

1. Petugas dapat melakukan pencarian buku.

2. Peminjam buku dapat melakukan pencarian buku.

B. Halaman Petugas Perpustakaan

1. Petugas Perpustakaan Login.

2. Petugas mengelola Data Pengadaan Buku.

3. Petugas mengelola Data Anggota.

4. Petugas mengelola Data

Transaksi Peminjaman Buku.

5. Petugas mengelola Data Transaksi

Pengembalian Buku.

6. Petugas mengelola Data Laporan

Pengadaan Buku.

7. Petugas mengelola Data

Laporan Peminjaman Buku.

8. Petugas Logout.

C. Halaman Anggota Perpustakaan

1. Calon Anggota Perpustakaan dapat melihat katalog pencarian buku.

2. Calon Anggota Perpus dapat melakukan pendaftaran Anggota perpus melalui petugas perpustakaan.

3. Anggota Perpustakaan dapat melakukan transaksi peminjaman buku melalui petugas perpustakaan.

4. Anggota Perpustakaan dapat melakukan transaksi pengembalian buku melalui petugas perpustakaan.

\subsection{Activity Diagram Sistem Informasi Perpustakaan}

Untuk menggambarkan alur kerja pada sistem informasi perpustakaan penulis menggunakan activity diagram. Diagram yang memvisualkan karakter dinamis dengan alamiah merupakan sistem yang rancang berupa sebuah model gerakan dan melakukan proses pemeriksaan dari kegiatan ke kegiatan yang lainnya. Dan Activity Diagram memiliki teknik dalam memvisualkan logical procedural, proses bisnis, dan alur kerja. Memiliki peran yang mirip seperti aliran diagram dalam hal memainkannya. Hanya saja terdapat perbedaan pandangan antara aliran diagram dengan notasi diagram alir yang membantu behavior paralel (Simanullang, 2021). Workflow yang menggambarkan aktivitas pada proses bisnis ataupun menu yang terdapat sistem perangkat lunak. Bukan aktivitas apa yang dijalankan oleh aktor, tetapi aktivitas yang dijalankan pada sistem (Afifah \& Setyantoro, 2021). Alur kerja yang mengikuti masing-masing use case. Tahapan penjabaran yang melingkupi activity pada use case. Sebuah diagram yang memiliki tipe karakteristik dari sebuah diagram state yang menunjukkan aliran kegiatan lainnya pada suatu sistem. Diagram yang memberikan tekanan pada sistem aliran terarah antar objek pada fungsi pemodelan (Edi Junaedi, 2021).

\subsection{Activity Diagram Sistem Usulan}

1. Activity Diagram halaman katalog pencarian buku

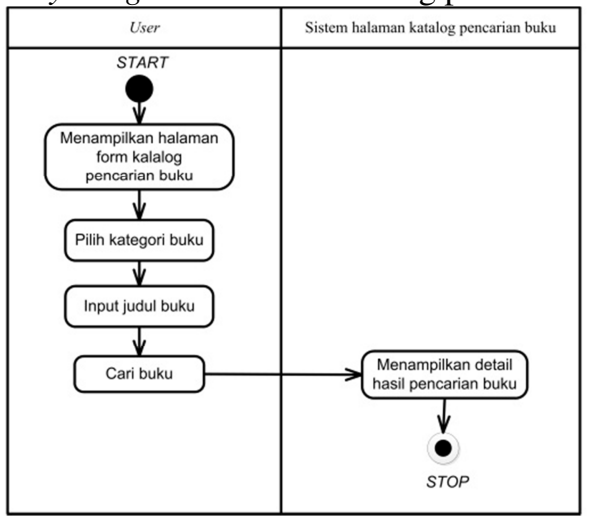

Gambar 2 Activity Diagram halaman katalog pencarian buku.

2. Activity Diagram Login Admin

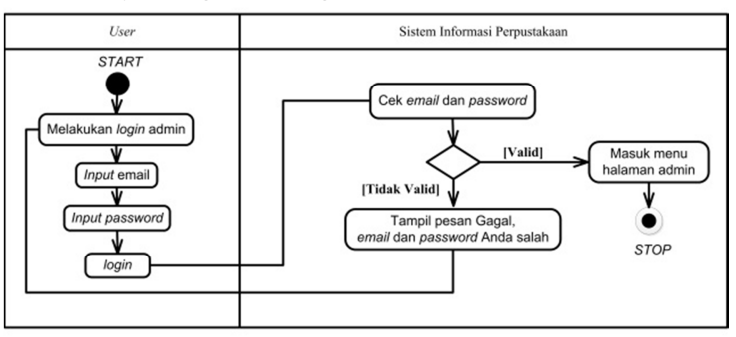

Gambar 3 Activity Diagram Login Admin

3. Activity Diagram Pengadaan Buku

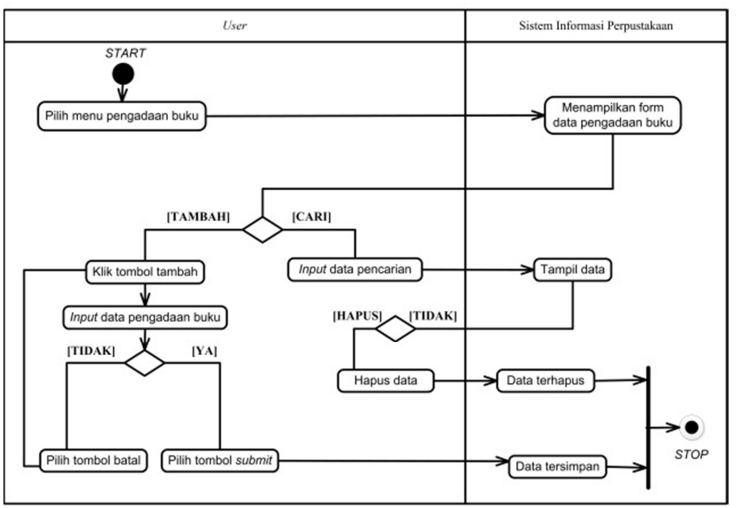

Gambar 4 Activity Diagram Pengadaan Buku

\section{Activity Diagram Tambah Anggota}

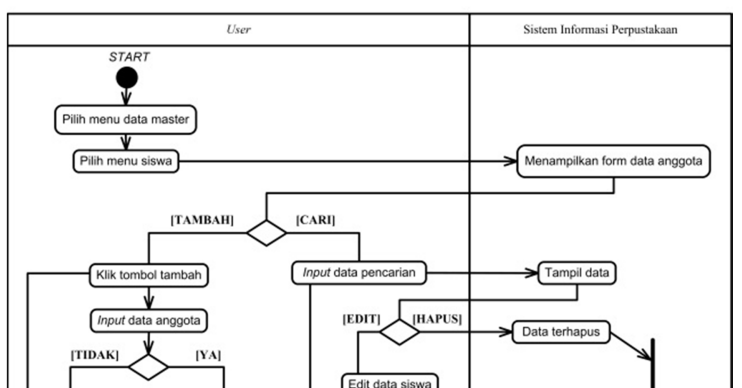


Gambar 5 Activity Diagram Tambah Anggota

5. Activity Diagram Transaksi Peminjaman Buku

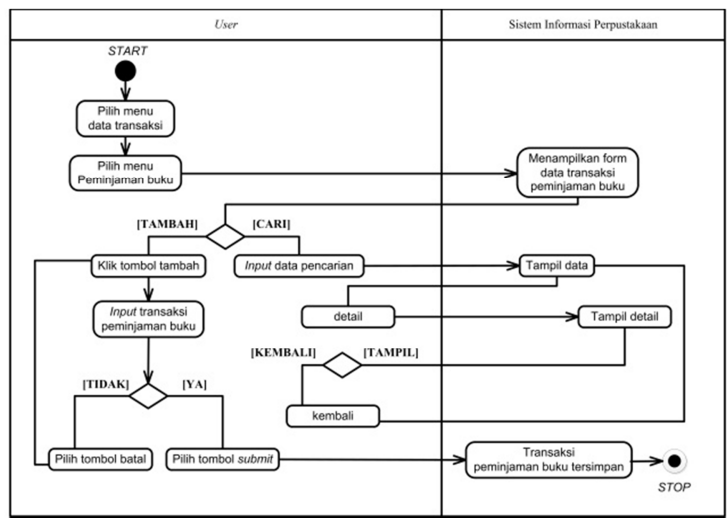

Gambar 6 Activity Diagram

Transaksi Peminjaman Buku

6. Activity Diagram Transaksi Pengembalian Buku

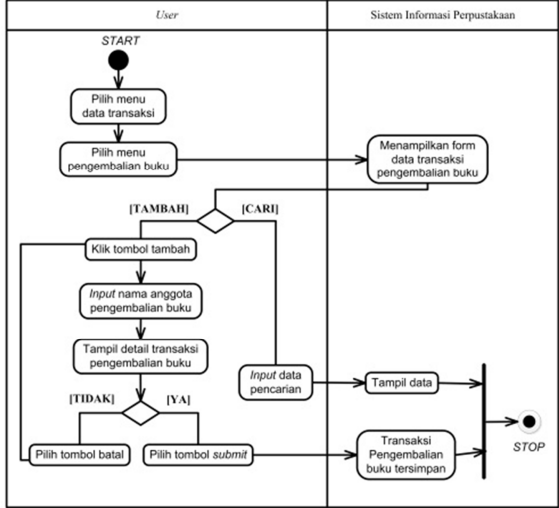

Gambar 7 Activity Diagram

Transaksi Pengembalian Buku
Gambar 8 Activity Diagram

Laporan Pengadaan Buku

3.6. Sequence Diagram

1. Sequence Diagram Transaksi Peminjaman Buku

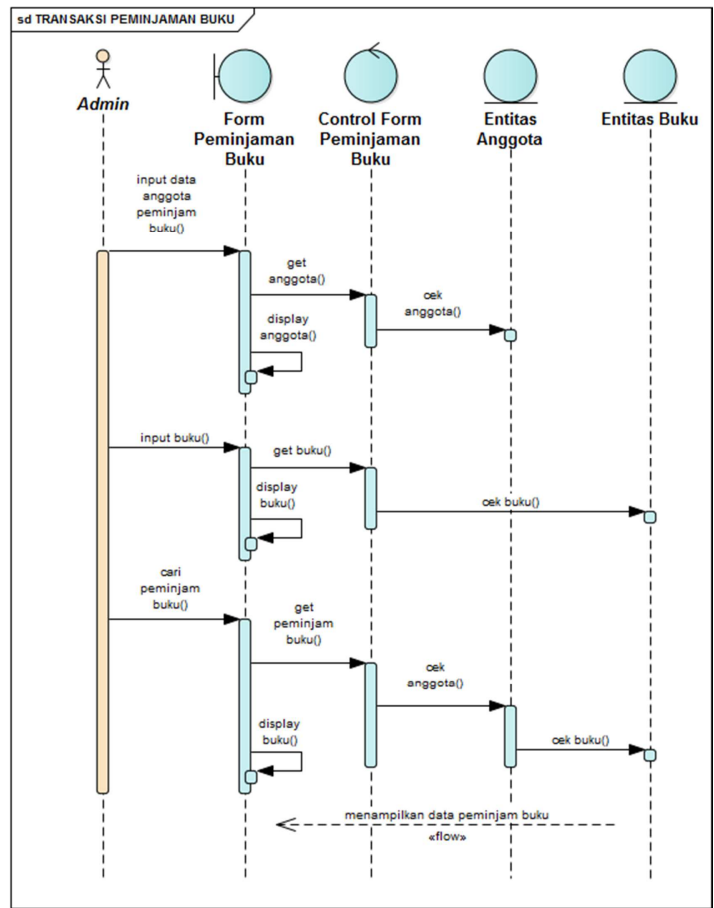

Gambar 9 Sequence Diagram

Transaksi Peminjaman Buku

2. Sequence Diagram Transaksi Pengembalian Buku

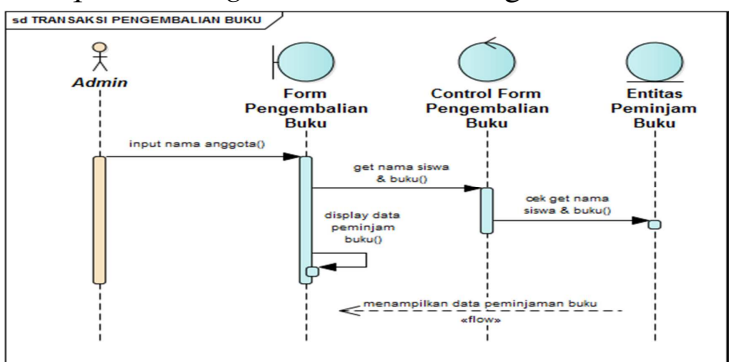

Gambar 10 Sequence Diagram Transaksi Pengembalian Buku

Menurut (Ansori, 2020) mengemukakan Bahwa Sequence Diagram menguraikan interaksi sebuah objek dan saling berkomunikasi antara objek-objek tersebut dan memberikan suatu tanda 
ataupun petunjuk. Sequence Diagram dimanfaatkan sebagai penjelasan perilaku yang ada pada skenario dan mengilustrasikan dengan cara entitas dan sistem saling berinteraksi, dan juga pesan yang digunakan pada saat berinteraksi. Seluruh pesan diilustrasikan pada suatu urutan saat eksekusi.

\subsection{User Interface (UI)}

Untuk mempermudah pengguna dalam memahami sebuah sistem informasi perpustakaan penulis menerapkan user interface. Desain penerapan rancangan yang diusulkan supaya sinkron dengan keinginan pemakai diharapkan memiliki kesesuaian dengan rencana dapat berjalan dan memberikan solusi pada permasalahan yang terjadi. Agar rangkaian elemen mudah dipahami dan dapat diakses User Interface (UI) digunakan sebagai sebuah fasilitas dari langkah untuk mengantisipasi apa sedang dilakukan oleh pemakai (Hidayat \& Hati, 2021).

1. User Interface Halaman Katalog Pencarian Buku. Halaman ini berisi jenis buku yang tersedia pada perpustakaan, dan user dapat melakukan pencarian buku melalui form pencarian dengan cara memilih kategori yang telah disediakan ataupun input langsung buku yang diinginkan sesuai dengan kebutuhan.

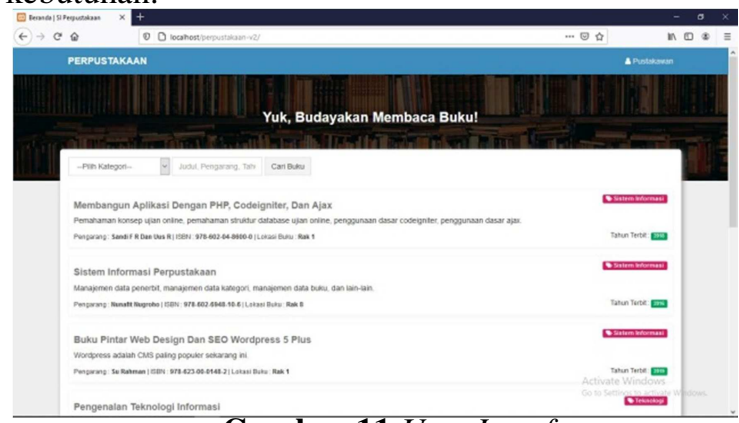

Gambar 11 User Interface

Halaman Katalog Pencarian Buku

2. Halaman Login Admin atau Login Petugas Perpustakaan. Admin atau petugas Perpustakaan dapat melakukan login pada sistem informasi perpustakaan untuk melakukan proses pengadaan buku, pendaftaran anggota baru, transaksi peminjaman buku, transaksi pengembalian buku dan membuat laporan.

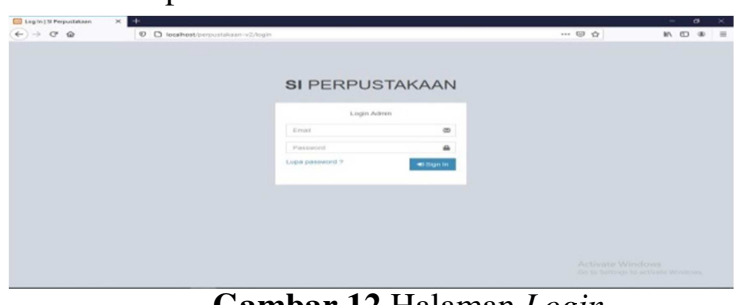

Gambar 12 Halaman Login

Admin atau Login Petugas Perpustakaan

3. Halaman Transaksi Peminjaman Buku. Admin atau petugas perpustakaan dapat melakukan pengelolaan transaksi peminjaman buku perpustakaan pada sistem informasi perpustakaan.

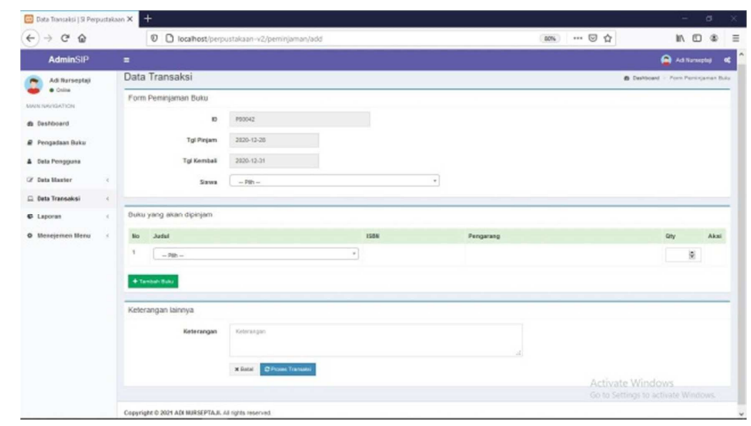

Gambar 13 Halaman Transaksi Peminjaman Buku

4. Halaman Laporan Pengadaan Buku. Admin atau petugas perpustakaan dapat melakukan pengelolaan laporan pengadaan buku perpustakaan pada sistem informasi perpustakaan.

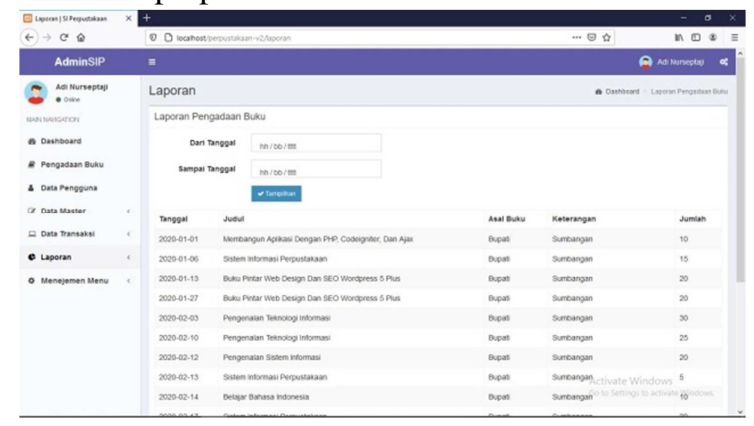

Gambar 14 Halaman Laporan Pengadaan Buku

\subsection{Blackbox Testing}

Tabel 1. Hasil pengujian blackbox testing peminjaman buku

\begin{tabular}{ccll}
\hline No & $\begin{array}{c}\text { Kondisi } \\
\text { Pengujian }\end{array}$ & \multicolumn{1}{c}{$\begin{array}{c}\text { Hasil yang } \\
\text { diharapkan }\end{array}$} & $\begin{array}{c}\text { Hasil } \\
\text { Pengujian }\end{array}$ \\
\hline 1 & $\begin{array}{l}\text { Jika nama siswa } \\
\text { tidak diisi }\end{array}$ & $\begin{array}{l}\text { Sistem menolak, } \\
\text { muncul pesan } \\
\text { "Siswa wajib diisi" } \\
\text { Sistem menolak, } \\
\text { muncul pesan "buku } \\
\text { wajib diisi" }\end{array}$ & Sesuai \\
& $\begin{array}{l}\text { Jika nama buku } \\
\text { tidak diisi }\end{array}$ & $\begin{array}{l}\text { Sistem akan } \\
\text { menolak muncul } \\
\text { pesan "Qty wajib } \\
\text { diisi" }\end{array}$ & Sesuai \\
& Jika jumlah \\
buku tidak diisi & &
\end{tabular}

\section{PENUTUP}

\subsection{Kesimpulan}

Sistem Informasi Perpustakaan dapat menjalankan pelayanan yang ada pada instansi perpustakaan akan lebih mudah akurat cepat serta real time meningkatkan produktivitas dengan dukungan software yang sesuai. Dan penulis menyimpulkan pada rancangan sistem informasi perpustakaan berikut ini:

1. Rancangan Sistem Informasi Perpustakaan menggunakan metodologi waterfall, sebagai pemodelan perangkat lunak menggunakan unified modeling language. 
2. Rancangan Sistem Informasi Perpustakaan dapat meminimalisir terjadinya kesalahan yang dapat terjadi pada pengelolaan data yang ada pada perpustakaan seperti data anggota, data buku, ataupun laporan dengan adanya sistem yang terkomputerisasi.

3. Mempermudah untuk pengelolaan data yang ada pada perpustakaan dengan menggunakan pengarsipan data pada perangkat atau media penyimpanan yang ada pada komputer lebih efisiensi waktu dan lebih aman.

4. Program sistem informasi perpustakaan mengimplementasikan menu login dengan input email dan password sehingga data dan informasi yang ada pada perpustakaan akan lebih aman.

5. Memberikan tujuan dengan penerapan sistem informasi agar pengelolaan data dan informasi pada perpustakaan lebih cepat.

6. Memberikan waktu pembuatan laporan secara cepat serta akurat sehingga informasi yang disampaikan akan lebih baik.

\subsection{Saran}

1. Sistem Informasi Perpustakaan dapat terus diperbaharui secara keseluruhan agar sistem dapat berjalan secara komprehensif dan dapat diimplementasikan pada organisasi perpustakaan.

2. Sistem Informasi Perpustakaan dapat terus dikembangkan dan maintenance secara berkala sesuai dengan kebutuhan user seperti pada tampilan ataupun pada fungsi yang terdapat pada sistem informasi perpustakaan.

3. Melakukan pelatihan kepada user ataupun sumber daya manusia tentang bagaimana menjalankan sebuah sistem informasi perpustakaan agar sistem dapat dijalankan secara produktif dan mendapatkan hasil yang lebih optimal.

\section{DAFTAR PUSTAKA}

Simarmata, J. (2021). Pengantar Teknologi Informasi (R. Watrianthos (ed.)). Yayasan Kita Menulis. https://books.google.co.id/books?hl=id\&lr=\&i $\mathrm{d}=$ BZUbEAAAQBAJ\&oi=fnd $\& p g=$ PA1 $1 \& \mathrm{dq}$ =penerapan+teknologi+informasi\&ots $=-$ xrsWnajlg\&sig=buI2bqA6CrqcasWUcLXFOzBtDU\&redir_esc $=\mathrm{y} \# \mathrm{v}=$ onep age \&q=penerapan teknologi informasi $\& \mathrm{f}=$ true

Agustiono, W., Fajrin, M. C., \& Rachman, F. H. (2021). Rencana Strategi Teknologi Informasi pada Perguruan Tinggi di Indonesia: Sebuah Tinjauan Pustaka. 10, 197-211.

W. A Probonegeoro, L. I. S. (2021). EVALUASI PENGELOLAAN TEKNOLOGI INFORMASI PADA PT. XYZ MULTIFINANCE PANGKALPINANG
DITINJAU DARI FRAMEWORK COBIT 4.0. Jurnal Informanika, 7(2407-1730), 4554.

Amelia, O., Putri, V., Wessiani, A., Sistem, T., Teknologi, I., \& Nopember, S. (2020). Analisis Kelayakan Finansial Proyek Pembangunan Jaringan Telekomunikasi di Kawasan Wisata Nusa Penida , Bali ( Studi Kasus : PT Telkom Indonesia ( Persero ) Tbk Witel Singaraja. 9(2).

Lamsah, M. S. (2021). Tahap Kepuasan Pekerja di Sektor Awam Terhadap Latihan Secara Atas Abstrak The Level of Satisfaction of Employees in the Public Sector on Online During Pandemic COVID-19 in Malaysia Abstract Keywords: COVID-19, online training, training module, traini. 6(1), 27-39.

Fahrizandi, F. (2020). Pemanfaatan Teknologi Informasi di Perpustakaan. Tik Ilmeu : Jurnal Ilmu Perpustakaan Dan Informasi, 4(1), 63. https://doi.org/10.29240/tik.v4i1.1160

Christianto, E., \& Santosa, J. (2018). Perancangan Arsitektur RESTful pada Integrasi Data Refrensi Buku di Perpustakaan Daerah dan Perpustakaan Universitas (Studi Kasus: Kota Salatiga). Pustabiblia: Journal of Library and Information Science, 2(1), 1.

Chaidir, Indra, D. W. A. (2020). Rancang Bangun Sistem Informasi Perpustakaan Berbasis Web. 5(2), 1-6.

Nurmansyah, W. N. C. (2021). RANCANG BANGUN SISTEM INFORMASI PERPUSTAKAAN MI ASSA ' ADIYAH ATTAHIRIYAH. 1436-1441.

Rahmawati, N. A., \& Bachtiar, A. C. (2018). Analisis dan perancangan sistem informasi perpustakaan sekolah berdasarkan kebutuhan sistem. Berkala Ilmu Perpustakaan Dan $\begin{array}{lll}\text { Informasi, } & \text { 14(1), }\end{array}$ https://doi.org/10.22146/bip.28943

Effendy, A. A., \& Sunarsi, D. (2020). Persepsi Mahasiswa Terhadap Kemampuan Dalam Mendirikan UMKM Dan Efektivitas Promosi Melalui Online Di Kota Tangerang Selatan. JURNAL ILMIAH MEA (Manajemen, Ekonomi, Dan Akuntansi), 4(3), 702-714. https://journal.stiemb.ac.id/index.php/mea/arti cle/download/571/248

Rada. (2021). Teknik Pengumpulan Data. Dosenpintar.Com.

https://dosenpintar.com/teknik-pengumpulandata/

Maulia Usnaini, V. Y. (2021). Perancangan Sistem Informasi Pendataan Penduduk Berbasis Web Menggunakan Metode Waterfall. Jurnal Manajemen Informatika Jayakarta, 1, 36-55.

Irwanto. (2021). Perancangan Sistem Informasi Sekolah Kejuruan dengan Menggunakan Metode Waterfall (Studi Kasus SMK PGRI 1 Kota Serang-Banten). Lectura: Jurnal 
Pendidikan, Vol.12 No. 1, Februari 2021, 12(1), 86-107.

Maulia Usnaini, V. Y. (2021). Perancangan Sistem Informasi Pendataan Penduduk Berbasis Web Menggunakan Metode Waterfall. Jurnal Manajemen Informatika Jayakarta, 1, 36-55.

Solichin. (2021). Pengembangan dan Pengujian Aplikasi Pemesanan Makanan berbasis Website Menggunakan Metode Waterfall. Journal of Computer Science an Engineering (JCSE), 2(1), 40-50.

Nurmansyah, W. N. C. (2021). RANCANG BANGUN SISTEM INFORMASI PERPUSTAKAAN MI ASSA ' ADIYAH ATTAHIRIYAH. 1436-1441.

Herlita, Yoland, A. O. S. (2021). PERANCANGAN SISTEM INFORMASI PEMBAYARAN SPP BERBASIS WEBSITE PADA SMA FAJRUL ISLAM JAKARTA. Jurnal PROSISKO, 8(1).

Hartopo, Sofian Winardi, A. H. (2020). Penerapan Metode Forward Chaining Untuk Mendiagnosa Penyakit Kulit Pada Manusia. Jurnal Mahasiswa Aplikasi Teknologi Komputer Dan Informasi Vol., 2(3), 77-82. https://doi.org/10.19184/isj.v5i3.20237

Simanullang, N. H. (2021). SISTEM INFORMASI PEMESANAN MENU MAKANAN PADA RM SEDEP ROSO RANTAUPRAPAT BERBASIS WEB. 1, 12-18.

Afifah, V., \& Setyantoro, D. (2021). Rancangan Sistem Pemilihan dan Penetapan Harga dalam Proses Pengadaan Barang dan Jasa Logistik Berbasis Web. Jurnal IKRA-ITH INFORMATIKA, 5(2), 108-117.

Edi Junaedi, F. W. (2021). PENGEMBANGAN METODE PEMBELAJARAN HURUF HIJAIYAH DENGAN SMARTPHONE ANDROID. JURNAL NUANSA INFORMATIKA, 15(1), 16-22.

Ansori, A. (2020). Pengertian Sequence Diagram: Tujuan, Simbol, dan Contohnya. Ansoriweb.Com.

https://www.ansoriweb.com/2020/04/pengertia n-sequence-

diagram.htmlhttps://doi.org/10.18326/pustabib lia.v2i1.1-24

Hidayat, N., \& Hati, K. (2021). Penerapan Metode Rapid Application Development ( RAD ) dalam Rancang Bangun Sistem Informasi Rapor Online ( SIRALINE ). 1, 8-17. 